\title{
EDUCAÇÃO PERMANENTE DOS SERVIÇOS PÚBLICOS DE SAÚDE DE FLORIANÓPOLIS, SANTA CATARINA
}

\author{
PERMANENT EDUCATION IN THE PUBLIC HEALTH SERVICES IN FLORIANÓPOLIS, \\ SANTA CATARINA
}

\author{
Mônica Motta Lino ${ }^{1}$ \\ Vânia Marli Schubert Backes ${ }^{2}$ \\ Fabiane Ferraz ${ }^{3}$ \\ Marta Lenise do Prado ${ }^{4}$ \\ Geani Farias Machado Fernandes ${ }^{5}$ \\ Luiz Anildo Anacleto da Silva ${ }^{6}$ \\ Daiana Kloh $^{7}$
}

Resumo O objetivo principal da Política Nacional de Educação Permanente em Saúde (PNEPS) é a formação e o desenvolvimento dos trabalhadores para o setor da saúde. A partir dos pressupostos dessa política, buscou-se analisar a realidade da educação permanente (EP) dos serviços públicos de saúde do município de Florianópolis, no estado de Santa Catarina, por meio de pesquisa descritiva de abordagem qualitativa. Realizou-se entrevista semiestruturada com 16 sujeitos responsáveis pelas iniciativas de EP da atenção básica, do setor hospitalar e órgão público municipal e estadual. A análise de conteúdo foi adotada como procedimento analítico dos dados, organizados em três categorias: planejamento das propostas de EP em saúde; metodologia e técnicas de ensino-aprendizagem utilizadas nas ações de EP; e avaliação do processo e dos resultados das ações de EP. Os resultados indicam que os serviços de saúde de Florianópolis caminham a passos lentos, mas progressivos, com iniciativas em EP interessantes, porém pontuais. Verificou-se que a EP não é priorizada frente ao 'ciclo vicioso' de dificuldades dos serviços de saúde. Logo, torna-se fundamental uma educação crítica e libertadora, que permita despertar mudanças nos trabalhadores, no ambiente de trabalho e usuários, com reflexos na qualidade dos serviços de saúde.

Palavras-chave educação continuada; políticas públicas de saúde; serviço hospitalar de educação.
Abstract The main objective of the National Policy for Permanent Education in Health (PNEPS) is qualifying and developing workers for the health sector. Base on the assumptions of this policy, an attempt was made to analyze the reality of permanent education (PE) in the public health services in the municipality of Florianópolis, state of Santa Catarina, via a qualitative descriptive survey. A semi-structured interview was carried out with 16 subjects who are in charge of the basic care PE initiatives, of the hospital sector and of municipal and state public agencies. Content analysis was adopted as the analytical data procedure, organized in three categories: planning of the PE in health proposals; the teaching and learning methodology and techniques used in PE actions; and the assessment of the PE action process and results. The results show that the health services in Florianópolis are progressing, even if slowly, with interesting, although punctual PE initiatives. It was seen that PE is not prioritized on account of the 'vicious cycle' of the difficulties in the health services. Therefore, it is fundamental to have a critical, freeing education, one that allows for the perception of changes among the workers, in the work environment, and among the users, with reflexes on health service quality.

Keywords continued education; public health policies; educational hospital service. 


\section{Introdução}

Em face da expansão progressiva e da organização dos serviços de saúde no Brasil, torna-se necessário que sejam articulados programas e conteúdos para os trabalhadores da saúde por meio de um processo educativo contínuo, a fim de que possam, além do desempenho rotineiro de suas atribuições, buscar essencialmente a melhoria do padrão de assistência à saúde e estruturação dos serviços.

A educação permanente (EP) aos trabalhadores da saúde, neste sentido, pode ser compreendida como um dispositivo para a transformação na área de saúde, para que eles próprios, usuários e cidadãos possam assumir maior controle sobre os fatores pessoais, socioeconômicos e ambientais que afetam o setor.

A Política Nacional de Educação Permanente em Saúde (PNEPS) considera que a EP em saúde é uma das estratégias que possibilita construir um novo estilo de gestão em que os pactos para reorganizar o trabalho na gestão, na atenção e no controle social são construídos coletivamente (Brasil, 2004a). Dessa forma, deve considerar as necessidades de saúde no âmbito local, ou seja, a partir da lógica da regionalização e da equidade.

A portaria $n .{ }^{\circ}$ 198, de 2004, do Ministério da Saúde (MS), anexo da PNEPS, criou, em todo território nacional, a estratégia dos Pólos de Capacitação de Educação Permanente em Saúde. Tal estratégia foi reelaborada e substituída a partir da portaria n. ${ }^{\circ} 1.996$, de 2007, sendo instituídas as Comissões Permanentes de Integração Ensino-Serviço e os Colegiados de Gestão Regional. Ambas as estratégias são dirigidas aos profissionais dos serviços de saúde, assim como buscam fortalecer a atenção básica de saúde, incluindo a formação profissional, o serviço, a gestão e o controle social como instâncias importantes para a efetiva consolidação do Sistema Único de Saúde (SUS) (Brasil, 2004b; 2007a).

A lei orgânica da saúde, n. ${ }^{\circ} 8.080$, de 1990, dispõe que a saúde é um direito fundamental do ser humano, devendo o Estado prover as condições indispensáveis ao seu pleno exercício, e a Norma Operacional Básica de Recursos Humanos do Sistema Único de Saúde (NOB/RH/SUS) apresenta-se como uma proposta de ação estratégica da política de desenvolvimento humano para o SUS (Brasil, 1990; 2000). Neste sentido, a partir dos anos 90, com a organização das ações de saúde no Brasil e a regulamentação do SUS, surge um novo tipo de usuário da saúde: mais participativo, com interesses voltados à realidade em que vive. Este usuário, ativo, pode facilitar as práticas de educação permanente em saúde quando há espaço para a sua participação ativa, visto que essas práticas são orientadas pelas necessidades e 
pela qualidade na atenção aos cidadãos, refletindo-se em melhorias das condições de vida e ampliação do exercício de cidadania.

Assim, o presente artigo deriva de uma pesquisa ${ }^{8}$ cujo objetivo foi analisar a realidade da educação permanente dos serviços públicos de saúde do município de Florianópolis, no estado de Santa Catarina. A partir dos resultados da pesquisa, intensificou-se um processo de contraponto entre a realidade encontrada em face da política nacional de educação permanente em saúde, elucidando os aspectos mais latentes e tornando-os mais visíveis. Longe de consolidar um processo estanque, visto que esta discussão é inacabada, o artigo tem a intenção de despertar novas formas de percepção de uma realidade, que pode, inclusive, ser comum a outros municípios do Brasil.

Para tanto, foi imprescindível compreender as estratégias da PNEPS, aprovada no ano 2004 e alterada pela portaria n. ${ }^{\circ}$ 1.996, de 2007 (Brasil, 2007a), cujo objetivo principal é a formação e desenvolvimento dos trabalhadores para o setor da saúde, com constantes processos educativos voltados à realidade de trabalho e ao contexto social destes sujeitos. Esta política visa a contribuir para transformar e qualificar a atenção à saúde, a organização das ações e dos serviços, os processos formativos, as práticas de saúde e as práticas pedagógicas (Brasil, 2004a; 2004b; 2007a).

Atualmente, é notável a insuficiente incorporação do conjunto de conhecimentos necessários para ocorrer uma verdadeira mudança na prática dos trabalhadores em saúde. Essa deficiência é ressaltada, levando-se em conta o predomínio da prática assistencial tradicional. Neste âmbito, tornase necessário ampliar as estratégias educativas, não só na dimensão técnica, mas também na subjetiva, de relação interpessoal e de humanização do serviço, voltada à realidade dos trabalhadores em saúde para a transformação desta realidade (Brasil, 2004b).

Para que seja possível construir esse novo modo de organizar e praticar a atenção em saúde, é necessário outro perfil de trabalho e de trabalhadores. Neste caso, a educação para o trabalho deverá pensar o trabalho e pensar a produção no mundo do trabalho. O objetivo, como ressaltado anteriormente, não é apenas formar bons técnicos, mas boas equipes, capazes de serem criativas no pensar, no sentir, no querer e no atuar (Brasil, 2004a). Para conquistar esse objetivo, é necessário promover a capacitação e o desenvolvimento das pessoas que trabalham na área da saúde, sendo a educação permanente uma possibilidade para o alcance deste objetivo (Brasil, 2004a).

Essa finalidade contempla vários obstáculos tanto no âmbito de construção como no de implementação da política de educação permanente em saúde, pois se necessita a priori da disponibilidade para o diálogo, para os interesses humanos, pois, como uma transformação político-social, deve 
partir da compreensão da realidade dos profissionais enquanto construtores da história, seres de decisão, da ruptura, da opção e da ética (Freire, 1996; Backes et al., 2003).

\section{Metodologia}

Trata-se de uma pesquisa descritiva de abordagem qualitativa. Os dados foram coletados a partir de entrevista semi-estruturada com 16 sujeitos coordenadores ou responsáveis pelo setor de educação permanente dos serviços públicos de saúde do município de Florianópolis, no estado de Santa Catarina.

Os serviços de saúde eleitos para o estudo (Quadro 1) foram constituídos por quatro hospitais públicos, quatro unidades locais de saúde (ULS, $\mathrm{ULS}_{2}, \mathrm{ULS}_{3}$ e ULS 4 ) e dois órgãos públicos - Secretaria Municipal de Saúde (SMS) e Secretaria Estadual de Saúde (SES) -, responsáveis pelas iniciativas de educação permanente no município e no estado, respectivamente. Três hospitais estão sob ingerência da SES ( $\mathrm{HP}_{1}, \mathrm{HP}_{2}$ e $\left.\mathrm{HP}_{3}\right)$, e o quarto é um hospital federal de ensino $\left(\mathrm{HP}_{4}\right)$. Todas as ULS são coordenadas pela SMS. Os sujeitos do estudo foram compostos por enfermeiros, médicos e nutricionistas, sendo importante salientar que tiveram seus nomes preservados, conforme preceitos éticos, por pseudônimos designados numericamente.

Quadro 1

\begin{tabular}{|c|c|c|c|c|c|}
\hline Instituição & Sujeitos & $\begin{array}{c}\text { Área de formação } \\
\text { dos sujeitos }\end{array}$ & $\begin{array}{l}\text { Atendimentos da } \\
\text { instituição por ano }\end{array}$ & $\begin{array}{l}\text { Número de } \\
\text { leitos }\end{array}$ & Particularidade \\
\hline $\mathrm{HP}_{1}$ & 01 e 02 & Médico e enfermeiro & 9.600 & 147 & $\begin{array}{c}\text { Referência em } \\
\text { doenças } \\
\text { contagiosas }\end{array}$ \\
\hline $\mathrm{HP}_{2}$ & 03 & Enfermeiro & 72.000 & 252 & Hospital Geral \\
\hline $\mathrm{HP}_{3}$ & 04 & Enfermeiro & 85.000 & 138 & $\begin{array}{c}\text { Referência } \\
\text { infantil }\end{array}$ \\
\hline $\mathrm{HP}_{4}$ & $\begin{array}{l}05,06,07 \\
08,09 \text { e } 10\end{array}$ & $\begin{array}{c}\text { Médico }(5,6,7) \text {, } \\
\text { enfermeiro }(8,9) \text { e } \\
\text { nutricionista }(10)\end{array}$ & 100.000 & 260 & $\begin{array}{c}\text { Hospital escola } \\
\text { federal }\end{array}$ \\
\hline SMS & 11 & Enfermeiro & --- & --- & Municipal \\
\hline
\end{tabular}


Continuaçåo - Quadro 1

\begin{tabular}{|c|c|c|c|c|c|}
\hline \multicolumn{6}{|c|}{ Caracterização dos serviços de saúde do estudo com respectivos sujeitos } \\
\hline Instituição & Sujeitos & $\begin{array}{c}\text { Área de formação } \\
\text { dos sujeitos }\end{array}$ & $\begin{array}{l}\text { Atendimentos da } \\
\text { instituição por ano }\end{array}$ & $\begin{array}{l}\text { Número de } \\
\text { leitos }\end{array}$ & Particularidade \\
\hline \multirow[t]{2}{*}{ SES } & 12 & Enfermeiro & --- & --- & Estadual \\
\hline & & & $\begin{array}{l}\text { População de } \\
\text { abrangência }\end{array}$ & & \\
\hline $\mathrm{ULS}_{1}$ & 13 & Enfermeiro & 12.317 & --- & $\begin{array}{l}\text { Residência em } \\
\text { ESF e RDA* }\end{array}$ \\
\hline $\mathrm{ULS}_{2}$ & 14 & Enfermeiro & 19.187 & --- & RDA \\
\hline $\mathrm{ULS}_{3}$ & 15 & Enfermeiro & 8.074 & --- & RDA \\
\hline $\mathrm{ULS}_{4}$ & 16 & Enfermeiro & 16.863 & --- & --- \\
\hline
\end{tabular}

Fonte: Lino, M.M.; Backes, V.M.S. A realidade da Educação Continuada/Permanente dos serviços públicos de saúde em Florianópolis. Relatório de Pesquisa - Pibic/CNPq. Florianópolis: Universidade Federal de Santa Catarina, 2006, 49 p.

*Rede Docente Assistencial (Convênio entre Universidade Federal de Santa Catarina e Secretaria Municipal de Saúde).

Os resultados e discussão das diferentes instituições estão apresentados concomitantemente, sem uma separação formal entre os sujeitos/instituições das áreas de atenção básica, hospitalar ou órgão público, visto que o intuito é traçar um panorama geral do município. Contudo, caso haja interesse, é possível identificar em qual área o sujeito encontra-se atrelado a partir da observação do Quadro 1.

A análise de conteúdo foi adotada como procedimento analítico dos dados coletados, visto que se trata de "um conjunto de técnicas de análise das comunicações, que utiliza procedimentos sistemáticos e objetivos de descrição do conteúdo das mensagens" (Bardin, 1977, p. 38). Este tipo de análise propõe compreender os conteúdos manifestos e ocultos, suas significações, ultrapassar o olhar imediato das aparências e estudar o problema a partir da própria expressão dos indivíduos. A sistemática para análise dos dados através desta técnica incluiu a pré-análise, a descrição analítica dos dados e a interpretação inferencial (Bardin, 1977).

Conforme prerrogativas da resolução CNS n. ${ }^{\circ}$ 196/96, todas as instituições e sujeitos aceitaram participar da pesquisa, autorizando, por meio do termo de consentimento livre e esclarecido, o uso das informações. Este estudo foi aprovado pelo Comitê de Ética em Pesquisa com Seres Humanos da Universidade Federal de Santa Catarina, conforme o processo n. ${ }^{\circ}$ 124/04. 


\section{Resultados e discussão}

No intuito de conhecer as propostas de educação permanente desenvolvidas nas instituições estudadas e estabelecer um panorama ou diagnóstico global, a análise de dados foi organizada a partir de três categorias, a saber: planejamento das propostas de educação permanente em saúde; metodologia e técnicas de ensino-aprendizagem utilizadas nas ações de educação permanente; e avaliação do processo e dos resultados das ações de educação permanente. As categorias serão apresentadas e discutidas a seguir:

\section{Planejamento das propostas de educação permanente em saúde}

Os sujeitos, a esse respeito, apresentaram discursos contraditórios. Por vezes, destacaram a existência de algumas iniciativas de planejamento mesmo que estanques e orientadas pelo imediatismo da necessidade, e outras vezes relataram não haver propostas, fato que aponta para uma ausência de sistematização das ações incorporadas às políticas institucionais dos serviços públicos de atenção à saúde, ou seja, a política de educação permanente em saúde que é realizada encontra-se aquém daquela orientada pelo Ministério da Saúde e Organização Pan-Americana da Saúde (Opas), presente na literatura.

O documento sobre polos de educação permanente em saúde (Brasil, 2004a) apresenta diretrizes para validação e acompanhamento dos projetos de educação permanente em saúde. Tais projetos devem conter:

a) apresentação da previsão de impactos: nas ações e nos serviços de saúde, na gestão do SUS, na educação técnica, na graduação, na pós-graduação, na educação popular e na produção e disseminação de conhecimento; b) definição dos compromissos dos parceiros participantes da estratégia da PNEPS: gestores, controle social, estudantes, instituições formadoras e hospitais de ensino ou outros serviços credenciados como de ensino; c) apresentação da amplitude das inclusões propostas: contemplar a multiplicidade de atores, de serviços e de práticas; d) formulação de abordagens e estratégias integradas de implementação educativa dos campos de conhecimentos específicos, reconhecidos como de interesse locorregional, estadual e nacional; e) explicitação das necessidades de saúde a que a proposta se reporta e das metodologias previstas; f) explicitação da relação da proposta com os princípios e diretrizes do SUS, o princípio de atenção integral à saúde e da cadeia de cuidados progressivos à saúde na rede do SUS; g) explicitação das mudanças nas práticas de saúde e de educação na saúde; h) explicitação da multiprofissionalidade e da transdisciplinaridade nas propostas; i) indicação dos responsáveis pela implementação 
de cada uma das ações previstas (instituição formadora, secretaria municipal, secretaria estadual etc.) com custos e plano de aplicação (Brasil, 2004a, p. 19-20).

A partir dessas diretrizes, reitera-se que a forma como estão sendo planejadas as ações de educação permanente em saúde nos serviços participantes do estudo em Florianópolis, tanto no setor hospitalar, quanto nas unidades locais de saúde, ainda se encontra distante do preconizado na PNEPS. A realidade encontrada neste município indica uma limitação do planejamento em ações isoladas, o que configura um processo de educação continuada segundo a PNEPS.

O processo de desenvolvimento da educação permanente, na realidade da maioria do setor hospitalar, encontra-se relegado a um plano secundário frente à evidência de muitos problemas e enfrentamentos considerados prioritários como falta de pessoal, desmotivação, sobrecarga de trabalho, entre outros.

Acho de suma importância o Serviço de Educação Permanente, porém lidamos com problemas sérios de falta de pessoal para a assistência e isto é visto como imprescindível ante a educação continuada por parte dos enfermeiros (Sujeito 3).

É difícil alcançar os objetivos de uma EP devido à dificuldade dos servidores participarem. (...) esta dificuldade é ocasionada pela desmotivação, mais de um vínculo empregatício e dificuldade de liberação. (...) Os servidores reclamam que não há cursos e treinamentos, mas quando os mesmos estão disponíveis não se comprometem (Sujeito 1).

Algumas vezes conseguimos alcançar nossos objetivos, mas gostaria de trabalhar para ter maior participação da equipe (Sujeito 2).

A maioria dos sujeitos responsáveis pelas iniciativas do setor hospitalar ressaltou que não existe um planejamento institucional e que os profissionais utilizam os momentos de passagem de plantão e reuniões, ou seja, aproveitam momentos durante as jornadas de trabalho para realizar o processo educativo. Quando solicitado um exemplo de EP, observa-se uma preocupação mais voltada à técnica.

As características expressadas convergem para o processo de educação continuada segundo a PNEPS, visto que ocorrem de forma desarticulada em relação à gestão, à organização do sistema e ao controle social, vindo de encontro ao que é compreendido como educação permanente pela política nacional. 
Não existe planejamento institucional para as atividades de educação permanente. (...) Utilizam-se reuniões, passagens de plantão, reuniões com servidores mesmo durante a jornada de trabalho. A implementação é organizada conforme as possibilidades do setor. O que se faz, na maioria das vezes, é a atualização de técnica de procedimentos (Sujeito 3).

Em relação à sistematização de um cronograma de atividades, essas iniciativas ainda não ocorrem de forma preestabelecida. O planejamento das atividades é feito de forma esporádica, não periódica e voltado à necessidade do momento.

Não temos um cronograma pré-estipulado. Normalmente é o profissional que vem procurar e daí nos organizamos. Desenvolvemos iniciativas de acordo com a necessidade (Sujeito 7).

Sujeitos indicaram que as capacitações são organizadas a partir das necessidades evidenciadas pelos trabalhadores, juntamente com as chefias, por meio do preenchimento de instrumentos no seu horário de trabalho.

Em contraponto à realidade até agora identificada, em algumas instituições investigadas observa-se, na enfermagem, uma preocupação de organização e continuidade das atividades junto aos trabalhadores, bem como um incentivo para o seu crescimento pessoal e profissional.

Realizamos um planejamento estratégico, que não visa somente ações que serão desenvolvidas este ano, mas sim as ações que serão desenvolvidas nesta atual gestão (Sujeito 9).

As propostas de educação permanente estão sendo discutidas através dos pólos de educação. As reuniões ocorrem uma vez por mês. O planejamento parte do serviço de RH (da instituição) de acordo com as necessidades dos setores e também de alguns organizados pela Secretaria Estadual de Saúde. Depois de elaborado, o projeto é discutido nas reuniões do pólo para ser pactuado. Os assuntos desenvolvidos são técnicos, gerenciais e também voltados para o desenvolvimento do ser humano como um todo (Sujeito 1).

Também é evidenciada a existência de uma preocupação e planejamento de atividades de educação permanente nos serviços na área médica. Quanto aos temas que são abordados, são mesclados assuntos técnico-científicos de acordo com a especialidade; outros mais genéricos, como ética; outros com interface em outras áreas, por exemplo, a jurídica; e ligados às mudanças de rotina no serviço. 
Na medicina são desenvolvidos cursos técnicos ou palestras, mas de interesse de todos os profissionais, como questões éticas e rotinas. No caso de estupro ou interrupção legal da gravidez, por exemplo, se trazem pessoas da área jurídica (Sujeito 10).

Um dos hospitais $\left(\mathrm{HP}_{1}\right)$ vem desenvolvendo junto aos trabalhadores afastados por licença de tratamento a saúde (LTS) uma série de práticas de inclusão, de acompanhamento e terapias alternativas para o autocuidado. Os discursos dos sujeitos ressaltam que o funcionário em licença fica esquecido e, quando retorna, vem desmotivado, sem vontade de trabalhar. Então foi criado um projeto de acompanhamento às pessoas afastadas. Esta iniciativa ocorreu entre uma parceria da gerência de enfermagem e profissionais do serviço social, visto que advém da área da enfermagem a maior parte dos afastamentos por problemas de saúde.

A assistente social realiza visitas em casa, telefona. Conversa com os que estão em atividade precisando de um diálogo amigo. Percebo que, com este serviço, estamos conquistando espaço entre os funcionários (Sujeito 1).

Outras iniciativas estão sendo realizadas conforme solicitação e ideias dos trabalhadores, como sessão de cinema, jornal RH, aulas de samba e reiki, curso sobre biossegurança, curso de informática, entre outros, revelando, conforme reitera Cordão (2000), uma busca de satisfação e valorização da pessoa no trabalho.

Estamos de braços abertos a todos e às ideias que nos chegam, colocando em prática o que no momento é viável, como sessão de cinema, aula de samba, curso de reiki, informática, biossegurança, direitos humanos e Aids, relações interpessoais, ética nas relações do trabalho, novas formas de gestão em saúde, entre outros (Sujeito 1).

Houve a exposição de algumas sugestões que na verdade representam um 'grito de alerta', de apoio para conseguir atingir os objetivos e provavelmente ampliar o leque de atividades e de demanda dos trabalhadores. Mesmo que a intenção talvez seja puramente reduzir o índice de afastamento, as consequências e reflexos dessas atividades implicam um processo de transformação do trabalho e das ações de saúde prestadas. Para tanto, é necessário ter uma infraestrutura física, financeira, de material e de equipamentos, no mínimo adequadas para o suporte de tais empreendimentos.

O processo de planejamento das ações de educação permanente desenvolvido nas ULS é relacionado intimamente às diretrizes da SMS 
(Lino et al., 2007). Os sujeitos revelaram existir um planejamento mensal de atividades nas próprias unidades, em nível central e também de forma ocasional.

A EP ocorre por meio de capacitações, treinamentos e atualizações, que são geralmente organizadas pela SMS em nível central. Às vezes, quando acontece algum congresso ou evento em Florianópolis em que a prefeitura esteja envolvida, geralmente têm-se algumas vagas para os funcionários que atuam na ponta, ou seja, nas unidades locais de saúde (Sujeito 15).

Em Florianópolis, as questões de EP ocorrem, de maneira geral, pontuadas pela necessidade local e também pela demanda política. Na unidade de saúde, temos mensalmente uma reunião de planejamento geral quando são levantadas as necessidades para atividades de EP junto aos funcionários. A implementação destas atividades é centralizada nas pessoas responsáveis, o trabalho é pouco compartilhado entre os membros da equipe. As demandas de atualização e reciclagem dos técnicos de enfermagem também são consideradas como atividades de educação permanente (Sujeito 16).

Os dirigentes dos serviços públicos tendem muito a ficar preocupados e ocupados com as questões administrativas, como aumento da área física, aquisição de novas tecnologias, entre outros. Embora tudo isso seja muito importante para o andamento da instituição, pois pode, consequentemente, melhorar a assistência prestada, não é possível deixar de considerar a importância que se deve dar aos trabalhadores das instituições, que se encontram desmotivados em virtude das questões sociopolíticas e econômicas, as quais assolam a maioria dos trabalhadores brasileiros (Pires, 1998). Não bastasse isso, o grau de conhecimento que possuem, por vezes, é defasado e geralmente adquirido por intermédio de uma educação bancária, na qual o professor 'ensina' e o aluno 'aprende', este se limitando a reproduzir o que aquele transmite, anulando qualquer iniciativa de criação e autoestímulo (Freire, 1996).

Quanto ao desenvolvimento de iniciativas de EP, há consenso entre as ULS quanto à falta de estímulo por parte da SMS - que muitas vezes apenas encaminha capacitações obrigatórias e padronizadas nacionalmente, pela gestão tripartite. Neste aspecto, desconsidera ações mais próximas às necessidades locais de saúde da população conforme preconiza a PNEPS (Brasil, 2004a).

Ainda é muito incipiente e não é desenvolvido de acordo com as necessidades do serviço. Está muito aquém das reais necessidades do serviço (Sujeito 13). 
Para o desenvolvimento da educação permanente, a ULS deve ter estrutura física, equipamentos, pessoal e fazer parte de sua missão (Sujeito 14).

A EP deveria ser frequente, planejada. Deveria ter um estímulo por parte da SMS para que o profissional se capacitasse cada vez mais. Por exemplo, eu desejava fazer uma especialização e pedi para que a prefeitura liberasse e auxiliasse com os custos da pós-graduação. Isto porque o conhecimento adquirido iria beneficiar o usuário da ULS, mas tive meu pedido negado (Sujeito 15).

Acredito que todos os serviços e instituições deveriam ter pessoas responsáveis por um setor de EP e fazer somente isso, para garantir o planejamento, implantação, implementação e avaliação de ações de educação (Sujeito 16).

Já os sujeitos responsáveis pelas atividades de EP em nível central, ou seja, na SMS e SES, consideram os cursos de gerenciamento, as oficinas locais e regionais de planejamento e programação como exemplos de atividades relacionadas à EP, visto que os mesmos foram discutidos e pactuados no antigo Pólo Locorregional de Educação Permanente do Litoral Centro-Catarinense.

Com relação aos pontos que poderiam ser modificados no serviço de EP, ambos os setores referem uma necessidade de maior planejamento em acordo com as necessidades locais dos serviços de saúde.

É preciso um planejamento mais baseado em necessidades locais, mas o MS exige o cumprimento de suas constantes demandas, que tomam todo o calendário anual. Por outro lado, é compreensível a exigência do MS, observando-se que possivelmente não ocorreria $\mathrm{EP}$ em grande maioria dos municípios se não fossem feitas de modo a cumprir metas programáticas vinculadas ao SUS (Sujeito 11).

Nos serviços de saúde de Florianópolis, percebe-se que os cursos e os eventos, inicialmente, são direcionados à organização das rotinas do setor $\mathrm{e}$ da parte física dos serviços para, posteriormente, voltarem-se às necessidades específicas de cada serviço, de cada trabalhador. Neste sentido, as primeiras iniciativas ocorrem a partir da solicitação de uma direção geral, mas, posteriormente, há um planejamento anual e os objetivos e necessidades são solicitados pelas chefias dos diferentes setores. Então, os responsáveis pela EP passam a organizar as ações via projeto para captação de recursos.

É necessário o projeto para conseguirmos as verbas para a melhoria da estrutura dos serviços, bem como para realimentar a estrutura dos projetos que já existem, 
que buscam uma maior motivação dos funcionários, que melhoram a qualidade de vida no trabalho, que melhoram as rotinas, que acabam chegando aos pacientes, ou seja, melhora o todo (Sujeito 8).

Ao avaliar a realidade de planejamento das ações de educação permanente nos serviços públicos de Florianópolis, é possível compreender que há uma necessidade de que as intervenções sejam articuladas. É fundamental que haja diálogo sobre as demandas dos trabalhadores, dos serviços e da população para configurar dispositivos de análise de ações, da possibilidade de integração e possível reforma no SUS (Ceccim, 2005).

\section{Metodologias e técnicas de ensino-aprendizagem utilizadas nas ações de educação permanente}

A metodologia adotada pelos serviços de saúde de Florianópolis ocorre, predominantemente, conforme o modelo tradicional, visto que as iniciativas são descendentes e padronizadas, legitimando-se enquanto educação continuada, segundo a PNEPS. Alguns sujeitos, no entanto, expressam em suas falas um movimento que assinala um processo de transformação metodológica orientado de modo participativo, ascendente e articulado ao contexto em que se situa, evidenciando características próprias da compreensão de educação permanente em saúde apregoada pela política nacional.

Nota-se que essa mudança se expressa na minoria da realidade dos serviços e de forma latente, porém significativa do ponto de vista do processo de transformação das ações de educação permanente em saúde, que parte de um sistema normativo para um sistema dialético, como consequência natural da movimentação histórica, política, social dos trabalhadores e usuários dos serviços de saúde.

O entendimento de alguns sujeitos acerca da educação permanente demonstrou uma visão mais ampliada, pois consideram que a EP desperta a consciência política e ética dos profissionais, abrangendo também a dimensão de treinamentos, atualizações no serviço, orientação introdutória de funcionários, bem como a participação em congressos, seminários e cursos de pós-graduação.

Apontam que, para os profissionais com nível superior, a busca de iniciativas de EP é mais comum, contudo essa procura relaciona-se mais à questão pessoal do que coletiva. Com a finalidade de prestar um atendimento melhor, a EP significa estar se inovando, proporcionando meios para os profissionais se atualizarem, reconhecendo a importância de todos os profissionais que trabalham com a saúde. 
A linha metodológica desenvolvida nas instituições é fruto de uma relação dinâmica e coletiva, que envolve vários aspectos: conhecimentos e experiências prévias dos sujeitos responsáveis pelo processo de EP; número de trabalhadores envolvidos; filosofia da instituição quanto à liberação de funcionários e incentivos ao processo educativo; entre tantos outros fatores que são descritos nesta discussão.

A metodologia é variada; algumas vezes, tradicional, através de aulas expositivas, e outras, através de oficinas e debates (Sujeito 1).

O programa de orientação introdutória trata de temas como: filosofia do hospital, ética, as diferentes avaliações que irão passar ao longo do seu trabalho dentro da instituição, mas tudo na forma de oficinas. Trata-se de algo bem lúdico... Então todas essas questões são apresentadas para o novo funcionário para que ele se sinta incluído na instituição (Sujeito 9).

Algumas especialidades mantêm continuamente abertura para profissionais de fora virem aqui fazer uma reciclagem por um período de três meses (Sujeito 7).

Nós temos duas formas: uma informal e assistemática, por meio de palestras ou reuniões científicas. E, sistematicamente, nós temos o planejamento de capacitação permanente do pessoal em atendimento de emergência - chamado Pals (Sujeito 6).

As reuniões que ocorrem nos hospitais envolvem a discussão de casos clínicos, organização do serviço de saúde e revisão de artigos científicos. Na própria reunião já são determinados o tema e os responsáveis para o próximo encontro, ou seja, há uma agenda com escala das pessoas sistematizada de uma reunião para a outra.

Existe sempre uma reunião mensal para todo corpo clínico, em que, num primeiro momento, ocorre a discussão de coisas próprias do serviço (administrativas) e, no segundo momento, atualização de temas que aparecem no dia-a-dia, como discussão de casos clínicos e revisões de artigos científicos (Sujeito 10).

Sempre existem pessoas escaladas para esta atividade de EP, elas é que irão organizar e apresentar para o grupo. Então se discute e se tiram conclusões, que irão ser aplicadas ou não, em benefício dos pacientes e do próprio serviço (Sujeito 6).

Alguns sujeitos mencionam que o planejamento das atividades é realizado conforme obrigatoriedade estabelecida pela Secretaria Estadual de 
Saúde, mas a metodologia é opção da instituição e oscila desde uma perspectiva adscrita ao método tradicional até a problematização e diálogo.

A EP ocorre conforme o planejamento estratégico do hospital (...) sendo algo obrigatório pela SES, qualificação admissional, palestras, encontros, oficinas. O propósito é educar, qualificar e desenvolver o ser humano. A metodologia às vezes é tradicional, com aula expositiva, mas outras vezes segue a teoria da problematização e construtivismo (Sujeito 2).

O depoimento explicita a valorização do trabalho e também do sujeito trabalhador, igualmente informa a utilização, mesmo que pontual, de metodologias problematizadoras, evidenciando o princípio mútuo de ensino e aprendizagem, bem como a participação e o diálogo como eixos norteadores deste processo (Reibnitz e Prado, 2006).

Em geral, as propostas de atualizações nos hospitais envolvem cursos, eventos, palestras e congressos na área e seguem algumas regras: o trabalhador tem liberdade de participar, mas precisa organizar suas atividades no trabalho, não tem dispensa, mas pode conseguir auxílio para os custos.

Em relação às atualizações, nós seguimos uma norma já estabelecida: neste ano eu participei de um congresso e ganhei ajuda de custo e a inscrição do congresso, mas geralmente a ajuda de custo é oferecida para quem vai apresentar trabalho (Sujeito 9).

Foi unânime a compreensão dos sujeitos, dentro do setor hospitalar, de que o processo de EP visa a enriquecer o trabalhador, possibilita mudanças pessoais e melhoria no atendimento dos usuários.

A EP traz contribuições ao lado profissional, visto que são novidades, atualidades, motivação (...) Após participarem de alguns cursos e eventos, vi funcionários se despertarem para as coisas - o que é necessário ser feito. Então, percebo que a EP traz mudanças, melhoria no comportamento das pessoas, no atendimento dos clientes. A EP é a união de todas estas palavras: associação, integração e atualização (Sujeito 8).

Neste aspecto, o propósito é atualizar o trabalhador e motivá-lo para que seja um participante ativo nas resoluções de problemas que ocorrem nas áreas e setores. O processo se desenvolve por meio de cursos e eventos que são organizados sob a forma de projetos e realizados como oficinas com dinâmicas de grupo.

Os assuntos abordados englobam questões de atendimento ao público, de relacionamento interpessoal e alguns específicos, de acordo com as 
necessidades de cada setor. A forma de desenvolvimento dos cursos geralmente privilegia dinâmicas vivenciais. Os eventos, além de atender a área científica relacionada à saúde, atingem outras esferas como datas comemorativas: o Dia do Enfermeiro, a Páscoa e o Natal, por exemplo, são denominados de 'dias temáticos'.

Há relatos de que antigamente ocorriam iniciativas de EP no modelo tradicional, no formato de cursos teóricos em que um técnico/especialista ministrava palestras para um grupo ouvir. Atualmente, mesmo não existindo um serviço de EP estruturado de modo formal, as iniciativas (ainda que na forma de cursos) acontecem com uma proposta metodológica diferenciada. Ocorrem de forma organizada, numa perspectiva participativa, dialogada, em que os trabalhadores participam ativamente do processo ensino-aprendizagem, em que se procura valorizar o conhecimento prévio de todos.

O que eu acho de inovador nesta proposta é que a gente saiu um pouco da questão de simplesmente passar informações e começamos a pensar mais no método. (...) estamos buscando construir conhecimentos com os nossos trabalhadores sem a obrigatoriedade de que um só lado esteja passando conhecimento e o outro recebendo, pois buscamos - desde o próprio nome do curso, que é 'Aprendendo e Ensinando' - a compreensão de que eles não são os expectadores que vão aprender, mas também são pessoas que ensinam (Sujeito 5).

A falta de estruturação de um serviço específico de educação permanente é ressaltada e reforça a necessidade de uma equipe responsável por esta atividade nas instituições, que organizaria as atividades e fortaleceria a assistência ao usuário.

Acredito que se tivesse um serviço de educação permanente estruturado os profissionais estariam mais aptos a prestar uma assistência de qualidade ao nosso usuário. Deveria ter uma equipe responsável pela educação permanente no hospital, com carga horária condizente com a atividade (Sujeito 4).

No desenvolvimento da EP, do ponto de vista da Secretaria Estadual de Saúde, há indicação de que este processo ainda acontece de maneira incipiente. Mas seguem na tentativa de implementação do modelo de planejamento e método das escolas de saúde pública e de formação em saúde, com avaliações no final de cada atividade.

O processo de EP ainda ocorre de forma incipiente e desarticulada. A escola de saúde pública e de formação em saúde vem construindo seus processos formativos na lógica da EP com cursos de capacitação para os servidores também nessa 
lógica. Neste processo, os novos servidores são levados a se colocarem como agentes ativos e críticos dentro do sistema de saúde (Sujeito 12).

Em geral, o processo de EP dentro das ULS é coordenado pela SMS a partir de um processo que vem pronto, com planejamento previamente instituído. O método adotado é voltado ao modelo tradicional de ensino, no formato de palestras e aulas expositivas, abordando assuntos relacionados com novas rotinas, normas, modelos e padronização.

Em nossa ULS, o processo educativo (treinamentos e cursos de capacitação) é ocasional, mas tem a finalidade de atualização técnica e padronização de procedimentos e serviços. São planejadas, implementadas e avaliadas pela Secretaria Municipal de Saúde, Setor de Desenvolvimento Institucional (Sujeito 14).

Aqui, a EP é caracterizada por treinamento, capacitação, atualização e conhecimento. Estas são direcionadas pela SMS (Sujeito 15).

Na prática, os métodos do construtivismo, da problematização e de valorização do ser humano (que levam em conta o conhecimento prévio dos trabalhadores), bem como o direcionamento dos processos educativos às necessidades locais, parecem estar distantes da realidade encontrada na atenção básica do município de Florianópolis. Contudo, o interesse da SMS e da SES converge para esta realidade, mas ainda a passos lentos.

Convém lembrar que a pedagogia da problematização aborda que, num mundo de mudanças rápidas, o importante não são os conhecimentos ou ideias, mas sim o aumento de capacidades que o profissional precisará para detectar problemas reais e buscar para eles soluções originais e criativas (Díaz-Bordenave e Pereira, 2005).

\section{Avaliação do processo e dos resultados das ações de educação permanente}

Os resultados quanto à realização de avaliação do processo de educação permanente nos serviços de saúde pública de Florianópolis revelam que não há avaliação formal com indicadores sobre os processos educativos realizados, bem como se houve transformações daqueles que participaram, tanto do ponto de vista pessoal quanto profissional. Como não há preocupação com a sistematização e continuidade das ações de EP, são grandes as dificuldades para instituir processos avaliativos, visto as propostas apresentarem um caráter pontual. Além disso, muitas vezes os dados coletados não são analisados pelos órgãos responsáveis. 
Assim, o que existe são as avaliações informais após cada atividade, com impresso próprio, no qual é possível - além das respostas específicas sobre o assunto - dar sugestões para os próximos cursos. Ainda, melhorias são percebidas no dia-a-dia, a partir de comentários entre a equipe de saúde e mudanças no desempenho dos trabalhadores.

Temos uma avaliação mais simples. Às vezes, depois de cada capacitação, nós temos um impresso de avaliação do curso. Formalmente ainda não ocorre. Em algumas ocasiões, observamos que determinado assunto, abordado em processos educativos por ser realizado de forma incorreta, o pessoal ainda faz do jeito anterior ao curso. Outras vezes, percebemos que houve uma melhora na atuação dos funcionários (Sujeito 9).

Neste aspecto, ressalta-se a importância da metodologia adotada. A falta de incorporação dos temas discutidos pode ter relação direta com o fato de os trabalhadores não se sentirem sensibilizados com a atividade educativa. Se estes não participam ativamente durante o processo, não ocorre a percepção da importância e do desvelamento crítico dos conteúdos na prática, ou seja, a metodologia adotada para a realização das atividades influencia no pensamento e reflete-se na ação - que é identificada pelo processo avaliativo. Assim, a importância da tríade planejamento-metodologia-avaliação torna-se uniforme e indispensável dentro da prática da educação permanente em saúde.

Nesta parte nós estamos falhos. Nós temos estas avaliações por escrito, mas realmente não se tem a análise destes dados. (...) na verdade, não está adiantando nós termos um pacote de avaliações sem análise, sem a tabulação dessas avaliações (Sujeito 8).

Evidencia-se a autocrítica ao processo por não possuir um estudo acerca das avaliações desenvolvidas, nem sobre a efetividade das metodologias utilizadas. Sobre este aspecto, cabe mais do que uma reflexão, torna-se necessário uma ação correspondente de trabalho.

Para avaliar as iniciativas ou os projetos em desenvolvimento - que muitas vezes são obrigatórios, como o exemplo do curso admissional -, algumas instituições utilizam um estudo dirigido sobre os aspectos trabalhados. A questão da frequência também é considerada importante. Conversas informais são realizadas, evidenciando se os participantes estão satisfeitos e interessados em participar. Os trabalhadores são avaliados e a participação é considerada hora trabalhada e, fora do horário de trabalho, é revertida em folgas. 
Avisamos o funcionário que ele será avaliado. Cada grupo apresenta sua produção e conseguimos avaliar como ocorreu a apreensão do conhecimento e sua postura. Ele tem que assumir a responsabilidade de frequentar todo o curso (Sujeito 5).

Na maioria das vezes, as avaliações ocorrem através da observação no decorrer do desenvolvimento do serviço. Já houve iniciativa (...) de fazer avaliação através de um pré-teste e pós-teste para verificação do aproveitamento do treinamento (Sujeito 1).

Vale ressaltar que todos os sujeitos mencionaram não existir nenhum processo formal de avaliação, mas expressaram que a mesma é importante, que têm isso como uma meta.

Quanto à satisfação dos participantes em relação às propostas de Educação Permanente, estas são muito relativas ao tipo de iniciativa empreendida.

Motivar os funcionários a participarem das capacitações é algo muito difícil. Quando se propõe um curso específico da área, a gente consegue participação, mas, se for um tema como relacionamento interpessoal, a participação já é mais difícil (Sujeito 8).

Em um aspecto geral, no setor hospitalar, os sujeitos têm um entendimento de satisfação na medida em que as chefias solicitam a continuidade de algumas atividades. Mas esta satisfação não é direta do trabalhador e, sim, das direções, que percebem resultados práticos dos processos educativos.

Já na atenção básica, todos os sujeitos referem que cabe à assessoria institucional estabelecida na SMS a elaboração de questionários avaliativos das atividades de educação permanente. Esse fator é consequência natural, visto que é a SMS que realiza o planejamento e metodologia dessas atividades. Geralmente, as propostas educativas vêm prontas para serem ministradas por profissionais da própria ULS, ou pessoas provenientes da SMS. A avaliação que existe geralmente é conduzida de várias formas: por meio da observação, questionário, observação durante o trabalho, porém já está se pensando em outras maneiras de avaliação. Assim, nos momentos em que ocorre uma avaliação das ações de EP, a maioria segue uma lógica tradicional, estando ainda no plano da reflexão a implementação de outros modelos com caráter mais emancipatório.

No entanto, para que sejam identificados os efeitos das ações desenvolvidas no campo da educação permanente em saúde, são necessários mecanismos de avaliação dos processos desenvolvidos, assim como mecanismos de monitoramento que possibilitem ordenar e/ou reordenar cada 
articulação intersetorial na política de formação para a área da saúde. A avaliação do processo deve considerar a realidade social e política na qual o serviço se encontra, verificando as necessidades em saúde, para que novas propostas pedagógicas sejam desenvolvidas e capazes de mediar a construção do conhecimento, no fortalecimento da ideia dos serviços de saúde enquanto espaços de aprendizagem (Ceccim e Feuerwerker, 2004).

(...) nas capacitações com a equipe da ULS, feitas no próprio local de trabalho, uma semana após o processo nós realizamos observação sistematizada, para avaliar a eficácia da atividade. Nas capacitações com a equipe de enfermagem, a avaliação é feita no final por questionário e por acompanhamento dos enfermeiros no seu setor de trabalho (Sujeito 4).

São realizadas avaliações ao término dos eventos, mas não há avaliação de impacto (Sujeito 12).

A avaliação das atividades educativas dentro da ULS ficam bastante soltas, geralmente realizadas individualmente, por questionário da SMS (Sujeito 16).

Existem diversas fragilidades no tocante ao processo avaliativo da educação permanente nos serviços de saúde de Florianópolis. Geralmente sendo conduzido de modo informal e individual, levando-se em conta aspectos produtivos do grupo como um todo. Contudo, os sujeitos reconhecem que esta modalidade avaliativa não é a mais apropriada e que precisa de mais atenção neste aspecto, o que implicaria atitudes pessoais de compromisso e responsabilidade de inclusão dos trabalhadores.

Assim, é necessário que sejam introduzidos nestes espaços iniciativas de avaliação voltadas à qualidade, circunscritas à dimensão objetiva, mas também subjetiva da qualidade, bem como suas possíveis combinações. Os desenhos avaliativos devem conferir singularidade aos programas de saúde, considerando o contexto do qual emerge, o que caracteriza uma proposta metodológica centrada na integralidade e humanização (Bosi e Uchimura, 2006).

Um processo de avaliação que inclui claramente a subjetividade das possíveis contribuições da educação permanente em saúde nos serviços precisa ter como pressupostos o reconhecimento do profissional em sua multidimensionalidade, diminuindo a distância entre a técnica e a afetividade.

Desta forma, a avaliação formal é indispensável para conhecer as repercussões do processo de educação permanente, bem como propor melhorias no planejamento e método do próprio processo - que se retroalimenta. Mas, além disso, é necessário levar em conta elementos teóricos conceituais inerentes à avaliação centradas na qualidade, integralidade e humanização, 
a partir de um processo que se volta ao alcance de fins articulados ao contexto no qual ocorre (Bosi e Uchimura, 2006).

\section{Considerações finais}

O processo de desenvolvimento da educação permanente nos serviços de saúde de Florianópolis orienta seu planejamento, metodologia e avaliação em acordo às demandas enviadas pelas direções em nível central ou necessidades pontuais despertadas na práxis cotidiana. Muitas vezes, esta educação é vista apenas como adequação de técnicas, revisão de protocolos, instituição de diretrizes ou capacitação de novos servidores. A metodologia tradicional de ensino é adotada, predominantemente, com palestras e aulas expositivas, sem processo avaliativo formal.

Distante do modelo concebido na Política Nacional de Educação Permanente em Saúde - que pressupõe educação crítica e libertadora, planejada em longo prazo conforme necessidades dos serviços, gestão, ensino e controle social, com processo avaliativo formal bem delineado -, Florianópolis encontra-se caminhando a passos lentos, mas progressivos, na busca de melhorias no descompasso realidade versus teoria.

Outros problemas de ordem administrativa e funcional têm sido os focos por parte da gestão nas instituições de saúde. Logicamente, são importantes, porém trata-se de atenuar problemas pontuais. Somente a educação pode transformar o pensamento individual e coletivo, despertar a revisitação interna de valores e gerar dispositivos de mudança no processo de trabalho e na qualidade dos serviços de saúde.

\section{Notas}

1 Bolsista de mestrado do CNPq. Membro do Grupo de Pesquisa em Educação em Enfermagem e Saúde do Programa de Pós-Graduação em Enfermagem da Universidade Federal de Santa Catarina (Eden/PEN/UFSC), Santa Catarina, Brasil. Mestranda do Programa de Pós-Graduação em Enfermagem da UFSC. <monicafloripa@hotmail.com> Correspondência: Rua Getúlio Vargas, 2620, Centro, São José, Santa Catarina, Brasil, CEP 88103-400.

2 Pesquisadora do CNPq. Professora adjunta da UFSC e vice-coordenadora do Programa de Pós-Graduação em Enfermagem da UFSC, Santa Catarina, Brasil. Líder do Grupo de Pesquisa em Educação em Enfermagem e Saúde do Programa de Pós-Graduação em Enfermagem da UFSC (Eden/PEN/UFSC). Doutora em Enfermagem pela UFSC. <oivania@nfr.ufsc.br> 
3 Bolsista de doutorado do CNPq. Membro do Grupo de Pesquisa em Educação em Enfermagem e Saúde do Programa de Pós-Graduação em Enfermagem da UFSC (Eden/PEN/UFSC), Santa Catarina, Brasil. Doutoranda do Programa de Pós-Graduação em Enfermagem da UFSC.<olaferraz@yahoo.com.br>

4 Pesquisadora do CNPq. Professora associada da UFSC e coordenadora do Programa de Pós-Graduação em Enfermagem da UFSC, Santa Catarina, Brasil. Vice-líder do Grupo de Pesquisa em Educação em Enfermagem e Saúde do Programa de Pós-Graduação em Enfermagem da UFSC (Eden/PEN/UFSC). Doutora em Enfermagem pela UFSC. $<$ mpradop@nfr.ufsc.br>

5 Professora adjunta I da Fundação Universidade Federal do Rio Grande (Furg), Rio Grande do Sul, Brasil. Doutora em Enfermagem pela UFSC. < geani@ vetorial.net>

6 Professor adjunto I da Universidade Federal de Santa Maria (UFSM), Santa Maria, Rio Grande do Sul, Brasil. Doutor em Enfermagem pela UFSC. <luiz.anildo@smail.ufsm.br>

7 Bolsista do Programa Institucional de Bolsas de Iniciação Científica do CNPq (Pibic/CNPq). Membro do Grupo de Pesquisa em Educação em Enfermagem e Saúde do Programa de Pós-Graduação em Enfermagem da UFSC (Eden/PEN/UFSC), Santa Catarina, Brasil. Graduanda em Enfermagem pela UFSC. <daianakloh@gmail.com>

8 Este artigo origina-se do projeto de pesquisa intitulado "A realidade da educação continuada/permanente dos serviços públicos de saúde em Florianópolis", concluído em 2006, financiado pela Fapesc e Pibic/CNPq e desenvolvido no Grupo de Pesquisas em Educação em Enfermagem e Saúde (Eden), do Programa de Pós-Graduação em Enfermagem da UFSC.

\section{Referências}

BACKES, Vânia Marli Schubert et al. Educação continuada: algumas considerações na história da educação e os reflexos na enfermagem. Texto \& Contexto Enfermagem, v. 12, n. 1, p. 80-88, 2003.

BARDIN, Lawrence. Análise de conteúdo. 7. ed. Portugal: Edições, 1977.

BOSI, Maria Lúcia Magalhães; UCHIMURA, Kátia Y. Avaliação qualitativa de programas de saúde: contribuições para propostas metodológicas centradas na integralidade e na humanização. In: BOSI, Maria Lúcia Magalhães; MERCADO, Francisco Javier (Orgs.). Avaliação qualitativa de programas de saúde: enfoques emergentes. Petrópolis: Vozes, 376 p., 2006.

BRASIL. Lei n. ${ }^{\circ} 8.080 / 90$, de 19 de setembro de 1990. Dispõe sobre as condições para a promoção, proteção e recuperação da saúde, a organização e o funcionamento dos serviços correspondentes e dá outras providências. Brasília, DF, 1990. 19 p. Disponível em: <http://portal.saude.gov.br/ portal/arquivos/pdf/LEI8080.pdf $>$. Acesso em: out. 2007.

Ministério da Saúde. Conselho Nacional de Saúde. Princípios e diretrizes para a NOB/RH-SUS. Brasília, DF, 2000. 159 p. 
Disponível em: <http://portal.saude.gov.br/ portal/arquivos/pdf/NOB/RH-SUS.pdf $>$. Acesso em: out. 2007.

Ministério da Saúde. Secretaria de Gestão do Trabalho e da Educação na Saúde. Departamento de Gestão da Educação na Saúde. Política de Educação e Desenvolvimento para o SUS: caminhos para a educação permanente em saúde: Pólos de educação permanente em saúde. Brasília, DF, 66 p., 2004a.

Ministério da Saúde. Portaria GM/MS no 198/04, de 13 de fevereiro de 2004. Institui a Política Nacional de Educação Permanente em Saúde - como estratégia do Sistema Único de Saúde para a formação e o desenvolvimento de trabalhadores para o setor e dá outras providências. Brasília, DF, 2004b. Disponível em: $<$ www.saude.gov.br/sgtes $>$. Acesso em: jul. 2004.

Ministério da Saúde. Portaria GM/MS no 1.996/07, de 20 de agosto de 2007. Dispõe sobre as diretrizes para a implementação da Política Nacional de Educação Permanente em Saúde. Brasília, DF, 2007a. Disponível em: <www.saude.gov.br/ sgtes>. Acesso em: ago. 2007.

CECCIM, Ricardo B. Educação permanente em saúde: desafio ambicioso e necessário. Interface: Comunicação, Saúde, Educação [Debate], v. 9, n. 16, p. 161-77, 2005.

CECCIM, Ricardo B.; FEUERWERKER, Laura C. Macruz. O quadrilátero da for- mação para a área da saúde: ensino, gestão, atenção e controle social. Physis: Revista de Saúde Coletiva, v. 14, n. 1, p. 4-65, 2004.

CORDÃO, Francisco Aparecido. Rumos da educação continuada na era do conhecimento. São Paulo: Centro Universitário São Camilo, 2000.

DÍAZ-BORDENAVE, Juan; PEREIRA, Adair Martins. Estratégia de ensino e aprendizagem. 25. ed. Petrópolis: Vozes, 2005.

FREIRE, Paulo. Pedagogia da autonomia: saberes necessários à prática educativa. 15. ed. São Paulo: Paz e Terra, 165 p., 1996.

LINO, Mônica Motta et al. 2007. A realidade da educação continuada na enfermagem nos serviços públicos de saúde de Florianópolis. Online Braz J. Nurs (Online), v. 6, n. 0, s/p. Disponível em: <www.uff.br/objnursing/ index.php/nursing/issue/view/5>. Acesso em: nov. 2007.

PIRES, Denise. Reestruturação produtiva e trabalho em saúde no Brasil. São Paulo: Annablume, 254 p., 1998.

REIBNITZ, Kenya S.; PRADO, Marta L. Inovação e educação em enfermagem. Florianópolis: Cidade Futura, 2006.

Recebido em 29/04/2008

Aprovado em 30/10/2008 